\title{
A Regression Model of the Prevalence Rate of VWF by Different Wrist Posture during Grinding Tasks
}

\author{
Seong Hwan Hwang ${ }^{1}$, Dong Choon Lee ${ }^{1}$, Hoon Yong Yoon ${ }^{1}$ \\ ${ }^{1}$ Department of Industrial \& Management Systems Eng., Dong-A Univ., Busan, Korea. \\ Shhwang@donga.ac.kr
}

\begin{abstract}
This study was performed to estimate the prevalence rate of VWF(vibration white finger) under different work posture while operating a light-weighted powered hand grinder. For the experiment, 8 different types of wrist posture(natural, unlar-flexion, radual-flexion, flexion, extension, complex posture, and etc.) and 3 types of feed force $(20[\mathrm{~N}], 50[\mathrm{~N}], 70[\mathrm{~N}])$ were considered. 10 male subjects were employed to polish metal plate with an 8-inch hand grinder. All of them were normal and healthy with no history and symptom of the work related musculoskeletal disorders in the dominant hand. Vibration acceleration data were recorded with sampling rate $2048[\mathrm{~Hz}]$. In addition, weighted R.M.S. accelerations at the tool were used to estimate factors from the recorded tri-axial vibration acceleration. The results indicate that controlled and free posture were lower hand other work posture, and as feed forces becomes larger the prevalence rate decreased.
\end{abstract}

Keywords: Work-related musculoskeletal disorders, Hand-arm vibration syndrome, Hand tool, Wrist posture, VWF(Vibration white finger)

\section{Introduction}

The powered hand tool gives the convenience and improves productivity. But the user can be exposed to the vibration due to the power. It can be said that the vibration of tool including the size, weight and shape of tool is one of major factors which increase cumulative stress of worker [1]. And also, this cumulative stress causes an occupational disease such as Hand-Arm Vibration Syndrome (HAVS) [2,3].

Moreover, Repetitive, sustained, and forceful movements of the wrist have been found to be important risk factors associated with work-related musculoskeletal disorders (WMSDs) such as carpal tunnel syndrome (CTS), tenosynovitis, tendinitis, and DeQuervain's disease [4,5]. Other epidemiological studies have further identified that awkward hand postures and highly dynamic wrist motions have a strong positive association with the prevalence of hand and wrist tendon disorders $[5,6]$. As a matter of fact, tendon disorders at the hand-wrist account for $55 \%$ of all WMSDs [5,7].

To understand transmitted vibration characteristics of the hand-arm system, weighted R.M.S. acceleration at the tool were used to calculated prevalence rate of VWF by different wrist posture. And also, this study was performed to develop regression model using body dimensions, wrist postures and feed forces.

\section{Method}

\subsection{Subjects}

Ten male university students were participated in this experiment. All of them were normal and healthy with no history of the musculoskeletal injury in the dominant hand. Their mean age was $26.4 \pm 1.2$ [yr], mean height: $176.83 \pm 3.43[\mathrm{~cm}]$, mean weight: $73.67 \pm 3.20$ $[\mathrm{kg}]$, mean hand length: $18.7 \pm 0.8[\mathrm{~cm}]$, maximum grip strength: $46.54 \pm 4.78[\mathrm{~kg} / \mathrm{f}]$.

\subsection{Apparatus and materials}

Experimental equipments used in this study include Martin type anthropometric set, and 4" hand grinder (BOSCH, 1.75kg), CAS electric scale for a controlling apparatus of pushing force, and Kistler Accelerometer, n-Code dAtagate, and Nsoft Vibration pick up and analysis system. Two types of piezo-electric accelerometer were used which has measurement range 500G(8790A500 type on the tool) and 50G(8690C50 type on the wrist). The subjects polish metal plate(25.5, shore hardness) with the grinder under the condition of barehanded. Fig. 1 shows the tools used in the experiment and material. And Fig. 2 shows representative experiments.
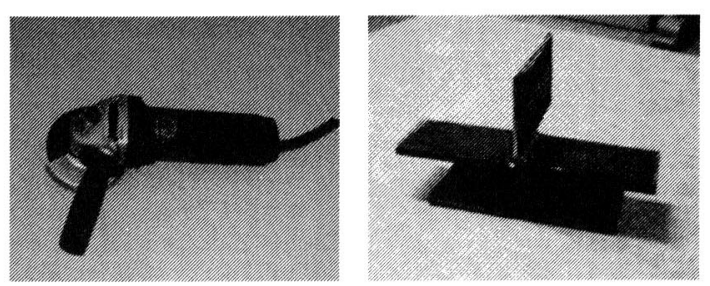

Fig. 1: Grinder and material which used experiment 

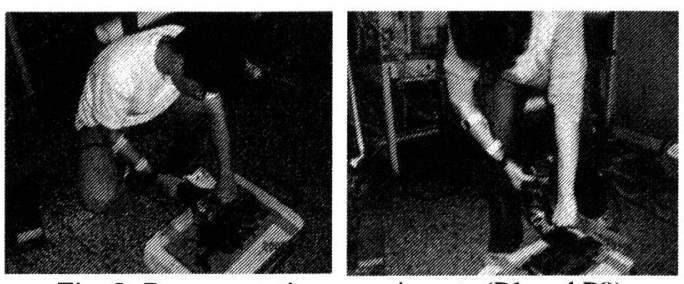

Fig. 2: Representative experiments (P1 and P8)

\subsection{Experiments and data analysis}

In this experiment, two independent factors were used such as wrist posture $\left(P_{1}\right.$ : natural position, $P_{2}$ : ulnar-flexion + extension, $P_{3}$ : ulnar-flexion + flexion, $P_{4}$ : ulnar-flexion, $P_{5}$ : radual-flexion, $P_{6}$ : vertical grinding, $P_{7}$ : controlled wrist position, and $P_{8}$ : free wrist position). And also, feed forces was tested $(20[\mathrm{~N}], 50[\mathrm{~N}]$, and $70[\mathrm{~N}])$.

Prior to the experiment, the purpose and procedure of the study were explained in detail to subjects. A hand dynamometer (JAMAR) was used to measure the maximum grip strength of the dominant right hand and basic anthropometric data was measured with the Martin type anthropometric set. Piezo-electric accelerometers were mounted on the tool and wrist (ulnar and radual position) as a anatomical and basic-centric co-ordinate systems for the hand [8]. Vibration data were recorded with sampling rate $2048[\mathrm{~Hz}]$. The subject took a rest for 5 min. after completing experiment and then next all random experiments were performed.

In addition, the un-weighted R.M.S. value at the acquisition points was used to evaluate the factors from the recorded tri-axial $\left(a_{x}, a_{y}, a_{z}\right)$ vibration acceleration [9]. Moreover, low frequency band under $6[\mathrm{~Hz}]$ was eliminated using the band-pass Fast Fourier Filter. The vibration data was transformed to weighted R.M.S. value by table 1 after $1 / 3$ octave frequency band analysis. And then each tri-axial data yas-compounded into weighted overall R.M.S. value $\left(\sqrt{a_{x}^{2}+a_{y}^{2}+a_{z}^{2}}\right)$. Table 2 shows the variables for making regression model.

Table 1. Frequency weighting factor at the $1 / 3$ octave band

\begin{tabular}{|c|c|}
\hline Nominal frequency[Hz] & Weighting factor \\
\hline 6.3 & 0.727 \\
8 & 0.873 \\
10 & 0.951 \\
12.5 & 0.958 \\
16 & 0.896 \\
20 & 0.782 \\
25 & 0.647 \\
31.5 & 0.519 \\
40 & 0.441 \\
50 & 0.324 \\
63 & 0.256 \\
80 & 0.202 \\
100 & 0.160 \\
125 & 0.127 \\
160 & 0.101 \\
200 & 0.0799 \\
250 & 0.0634 \\
315 & 0.0503 \\
400 & 0.0398 \\
\hline
\end{tabular}

\begin{tabular}{|c|c|}
\hline 500 & 0.0314 \\
630 & 0.0245 \\
800 & 0.0186 \\
1000 & 0.0135 \\
1250 & 0.00894 \\
\hline
\end{tabular}

Table 2. Selected variables for regression model

\begin{tabular}{|c|c|}
\hline Variable & Note \\
\hline $\mathrm{X} 1$ & Height $(\mathrm{cm})$ \\
\hline $\mathrm{X} 2$ & Weight(kg) \\
\hline $\mathrm{X} 3$ & Hand length $(\mathrm{cm})$ \\
\hline $\mathrm{X} 4$ & Hand width $(\mathrm{cm})$ \\
\hline $\mathrm{X} 5$ & Palm length(cm) \\
\hline X6 & Hand thickness $(\mathrm{cm})$ \\
\hline $\mathrm{X} 7$ & Palm circumference $(\mathrm{cm})$ \\
\hline $\mathrm{X} 8$ & Max. palm circumference $(\mathrm{cm})$ \\
\hline $\mathrm{X} 9$ & Wrist width $(\mathrm{cm})$ \\
\hline $\mathrm{X} 10$ & Wrist thickness $(\mathrm{cm})$ \\
\hline $\mathrm{X} 12$ & Feed force $(\mathrm{N})$ \\
\hline $\mathrm{X} 13$ & Ulna angle $\left(^{\circ}\right)$ in each experiment \\
\hline $\mathrm{X} 14$ & Radius angle $\left({ }^{\circ}\right)$ in each experiment \\
\hline $\mathrm{X} 15$ & Flexion angle $\left({ }^{\circ}\right)$ in each experiment \\
\hline $\mathrm{X} 16$ & Extension angle $\left({ }^{\circ}\right)$ in each experiment \\
\hline $\mathrm{X} 17$ & Max. ulna angle $\left({ }^{\circ}\right)$ in each experiment \\
\hline $\mathrm{X} 18$ & Max. radius angle $\left({ }^{\circ}\right)$ \\
\hline $\mathrm{X} 19$ & Max. flexion angle $\left({ }^{\circ}\right)$ \\
\hline $\mathrm{X} 20$ & Max. extension angle $\left(^{\circ}\right)$ \\
\hline $\mathrm{X} 21$ & Working direction(horizontal(1), vertical(2)) \\
\hline $\mathrm{Y}$ & Weighted RMS accel.(G) \\
\hline
\end{tabular}

\section{Results and discussion}

In this study, residual analysis was performed to evaluate the fitness of regression model by selected variables using Durbin-watson statistics. After that influence analysis by specified observation was carried out using Rstudent, Hat-dian H, Diffits and Dfbetas statistics. The variables of multiple regression model was selected by stepwise method from SAS 8.0.

Table 3. Mean prevalence rate( $10 \%)$ of VWF(4-h)

\begin{tabular}{|c|c|c|c|}
\hline Posture & Feed force(N) & Mean & S.D. \\
\hline \multirow{3}{*}{ P1 } & 20 & 3.44 & 1.10 \\
\cline { 2 - 4 } & 50 & 3.01 & 1.08 \\
\cline { 2 - 4 } & 70 & 4.01 & 1.27 \\
\hline \multirow{3}{*}{ P2 } & 20 & 3.48 & 0.85 \\
\cline { 2 - 4 } & 50 & 3.44 & 0.57 \\
\cline { 2 - 4 } & 70 & 3.86 & 1.08 \\
\hline \multirow{3}{*}{ P3 } & 20 & 3.52 & 1.26 \\
\cline { 2 - 4 } & 50 & 3.66 & 0.79 \\
\cline { 2 - 4 } & 70 & 4.54 & 1.18 \\
\hline \multirow{3}{*}{ P4 } & 20 & 3.80 & 0.92 \\
\cline { 2 - 4 } & 50 & 3.78 & 1.23 \\
\cline { 2 - 4 } & 70 & 4.37 & 0.95 \\
\hline \multirow{3}{*}{ P5 } & 20 & 3.30 & 0.87 \\
\cline { 2 - 4 } & 50 & 3.82 & 1.29 \\
\cline { 2 - 4 } & 70 & 4.39 & 1.26 \\
\hline \multirow{2}{*}{ P6 } & Type 1 & 3.74 & 0.73 \\
\cline { 2 - 4 } & Type 2 & 3.90 & 0.93 \\
\hline \multirow{2}{*}{ P7 } & Type 1 & 6.27 & 0.87 \\
\cline { 2 - 4 } & Type 2 & 5.88 & 1.24 \\
\hline \multirow{2}{*}{ P8 } & Type 1 & 5.55 & 1.14 \\
\cline { 2 - 4 } & Type 2 & 5.37 & 0.55 \\
\hline
\end{tabular}


Table 4. Result of ANOVA of $10 \%$ prevalence rate of VWF

\begin{tabular}{|c|c|c|c|c|c|}
\hline Source & DF & SS & MS & F & $\operatorname{Pr}>F$ \\
\hline $\mathrm{A}$ & 7 & 182.6637 & 26.09481 & 20.54 & $<.0001^{* *}$ \\
\hline $\mathrm{B}$ & 3 & 84.62432 & 28.20811 & 22.2 & $<.0001^{* *}$ \\
\hline $\mathrm{A}^{*} \mathrm{~B}$ & 10 & 16.88357 & 1.688357 & 1.33 & 0.2127 \\
\hline Error & 383 & 486.548 & 1.27036 & & \\
\hline Total & 403 & 770.7195 & & & \\
\hline
\end{tabular}

A : work postures ; B : push forces

$* *: p<0.01$

Table 3 shows the mean prevalence rate of VWF under the 4-hour working condition. And table 4 shows the results of ANOVA that independent variables significantly affect to the prevalence rate of VWF.

In the regression model, variable $\mathrm{Y}$ means the level of weighted R.M.S. acceleration and $\mathrm{D}$ is annual exposure duration which means the times to appear $10 \%$ $\operatorname{VWF}\left(10 \%\right.$ workers show temporary VWF). $\mathrm{T}_{0}$ means 8 hours $(28800 \mathrm{~s})$ and $\mathrm{T}_{\mathrm{i}}$ is daily exposure times by different wrist posture [10].

$$
D_{i}=31.8 \times\left[Y_{i} \times 9.8 \times \sqrt{\frac{T_{i}}{T_{0}}}\right]^{-1.06}
$$

The results by wrist postures $Y_{i}$ are as follows;

$$
\begin{aligned}
& P_{1}: \text { natural position } \\
& Y_{1}=-3.59-0.01 * \mathrm{X}_{2}-1.26 * \mathrm{X}_{3}+0.77 * \mathrm{X}_{11} \\
& P_{2}: \text { ulnar-flexion+extension } \\
& Y_{2}=0.27-0.03 * \mathrm{X}_{12}+0.02 * \mathrm{X}_{13} \\
& P_{3}: \text { ulnar-flexion }+ \text { flexion } \\
& Y_{3}=-0.93-0.01 * \mathrm{X}_{2}+0.55 * \mathrm{X}_{3}-0.09 * \mathrm{X}_{12} \\
& P_{4}: \text { ulnar-flexion } \\
& Y_{4}=0.68-0.02 * \mathrm{X}_{2}-1.49 * \mathrm{X}_{6}+0.24 * \mathrm{X}_{12} \\
& \quad+0.04 * \mathrm{X}_{13}
\end{aligned}
$$

$P_{5:}$ radual-flexion

$Y_{5}=-5.59+0.04 * \mathrm{X}_{1}-0.04 * \mathrm{X}_{2}$ $-0.95 * X_{5}+3.11 * X_{6}+0.85 * X_{10}$

$P_{6}$ : vertical grinding

$Y_{6}=-6.95+0.04 * \mathrm{X}_{1}-0.03 * \mathrm{X}_{2}$

$$
-0.58 * X_{5}+2.31 * X_{6}+0.32 * X_{10}
$$

$P_{7}$ : controlled wrist position

$Y_{7}=1.52+0.23 * \mathrm{X}_{4}+0.73 * \mathrm{X}_{9}-0.24 * \mathrm{X}_{11}$

$$
+0.06 * X_{21}
$$

$P_{8}$ free wrist position

$$
Y_{8}=0.72-0.01 * X_{1}+0.14 * X_{3}-0.03 * X_{18}
$$

\section{Conclusion}

This study was performed to estimate the prevalence rate of VWF(vibration white finger) under different work posture while operating a light-weighted hand grinder. The work posture was selected which have frequently occurred in the manufacturing industries.

The results are as follows:

(1) Estimation of the prevalence by working time.

Estimation value was significantly different by wrist postures and feed forces. Controlled and free posture were lower than others. And as feed force becomes larger, the prevalence rate decreased.

(2) Multiple regression model.

Body dimensions of subject, wrist angle, feed forces and etc. were used to develop regression model by multiple regression analysis.

Concludingly, we can see that working with controlled or free wrist posture is recommended since prevalence rate was lower than the others. And it is recommended that feed force is maintained level of 20 or $70[\mathrm{~N}]$. But further study is certainly needed for more heavy electric hand tools, and to evaluate the transmitted vibration level between tool and wrist and prevalence rate for the changing of Duncan's grouping .

\section{References}

[1] Schwartz W.H. Portable power \& hand tools and fasteners. Assembly Engineering. 9 (1989) 134-140

[2] Armstrong T.J. An ergonomic guide to carpal tunnel syndrome, American Industrial Hygiene Association Journal. 43-2 (1983) 103-116.

[3] Aghazadeh F. and Mital A. Injuries due to hand tools.Applied Ergonomics. 8-4 (1987) 273-278.

[4] Armstrong T.J., Foulke J.A., Joseph B.S., and Goldstein S.A. Investigation of cumulative trauma disorders in a poultry processing plant. American Industrial Hygiene Association Journal. 43 (1982) 103-116.

[5] Kong Y.K., Jang H.K., and Freivalds A. Wrist and tendon dynamics as contributory risk factors in work-related musculoskeletal disorders. Human Factors and Ergonomics in Manufacturing. 16-1 (2006) 83-105.

[6] Armstrong T.J. and Chaffin D.B. Some biomechanical aspects of the carpal tunnel. Journal of Biomechanics. 12 (1979) 567-570.

[7] Bureau of Labor Statistics. Reports on survey of occupational injuries and illnesses, Washington, DC, 1996.

[8] Griffin M.J. In: Handbook of Human Vibration. Academic Press Inc., San Diego, 1990, p. 536.

[9] International Organization for Standardization. Mechanical vibration-Guidelines for the measurement and the assessment of human exposure to hand transmitted vibration. ISO 5349. International Organization for Standardization, Geneva, 1986.

[10] KS B ISO 5349-1, Mechanical vibration - Measurement and evaluation of human exposure to hand-transmitted vibration - Part 1 : General requirement, KS, 2004. 